\title{
Learning French from a Dictionary
}

\section{An Essay on Utterance-Dependent Meaning ${ }^{1}$}

\section{Manfred Kupffer}

Er sagte "Wuih", denn er sprach perfekt französisch. Sie sagte "Biehn", denn sie kannte es nur aus Büchern.

\section{Introduction}

According to a widely accepted theory of reference (Kaplan 1989), the extension of a deictic (or indexical) word like $I$, you, here, now, etc. is always determined by the utterance situation. As a case in point, consider a classic exchange at Blenheim Palace: ${ }^{2}$

(1) Winston, if I were married to you l'd put poison in your coffee.

(2) Nancy, if I were married to you I'd drink it.

Obviously, it does not make much sense to claim that such a situation uniquely determines a referent for the words $I$ and you. For in her utterance of (1), Lady Astor (twice) uses the second person pronoun to address Winston Churchill, reserving the first person for reference to herself; whereas in his repartee Sir Winston uses the first person to refer to himself (twice) and the second person to denote the Viscountess. But then maybe the whole scene is not an utterance situation proper in that it contains more than one utterance, whereas in a proper utterance situation exactly one utterance ought to take place. Moreover, the famous utterances of (1) and (2) are part of different fragments of the same situation, and then maybe the denotations of the corresponding ut-

1 This paper was originally planned to be written in cooperation with Ede Zimmermann. Although, at some stage, Ede opted out (because he thought, erroneously, that there was not much left for him to do) the paper owes a lot to him. For example, the final theory in section 6 owes its existence to an extended interchange with Ede on the question. Although the proposal is my own, I would never have come up with it without Ede's pressing criticisms of former proposals of mine. Furthermore, Ede provided some examples in section 6, nearly all the examples in section 1, and the English in that section. I am grateful to Amim von Stechow, Wolfgang Spohn, Ulrike HaasSpohn, and Ede Zimmermann, who have commented on earlier written versions of my thoughts on this topic (as part of my dissertation).

2 Cf. http://winstonchurchill.org/bonmots.htm\#poison 
terances must be determined with respect to these fragments, rather than the situation at large. Following this train of thought, meanings would turn out to be functions assigning denotations (intensions or extensions) to fragments of situations, and these fragments are sufficiently finely grained so as to never include more than one complete utterance.

However, this strategy does not always work as smoothly as in the case at hand. To see this, imagine the following (unconfirmed) interruption of the above scene by the butler, who is carrying in a tray:

(3) This is your coffee, my lord - without sugar, as you requested, my lady.

Here too, the pronoun you obviously has two referents, viz., the very same ones as in the utterances of (1) and (2) considered above. Hence if one were to evaluate the two utterances of you with respect to different situation fragments, one would be at a loss when it comes to interpreting the entire utterance of (3). For whatever the relevant utterance situation may be, it cannot coincide with both fragments.

This phenomenon of switching reference within one utterance is well known. And it is not restricted to the second person. Here are some other cases:

(4) Course material is here and here.

(5) "I'll come frae the North."

"And I frae the South."

"And I frae the Forth."

(6) Now my shares are worth 150,000 dollars more than now.

(7) He is coming, but he isn't.

Even though (4) is a perfect illustration of Hegel's views on local deixis, its author is a contemporary logician, and the two occurrences of here relate to different (web) locations. Similarly, but even more outrageously, the three occurrences of $I$ in (5) respectively refer to the producers of the relevant sub-utterances: the text is taken from (William Yuill's translation of) Theodor Fontane's ballad Die Brück' am Tai, where three witches (?) combine their efforts to utter a single sentence. (6) may have been truthfully uttered by the founder of Microsoft Corporation on Monday, August 31, 1998 provided that he left two seconds between the first and the second occurrence of now, which would have been naturally construed as referring to the times at which they were 
uttered. And as Arnim invites us to imagine, (7) may well be uttered in order to express the proposition that Niko Dingsbums, but not Giovanni Tizio, is coming. ${ }^{3}$

Examples like (4)-(7) strongly suggest the following conclusion:

(a) In order to determine the denotation of an indexical expression, one must distinguish between different occurrences of that expression within the same sentence.

Bearing this in mind, the idea that deictic expressions depend on the utterance situation naturally turns into a more local principle:

(b) The denotation of the occurrence of an indexical expression depends on properties of the utterance of that occurrence.

Token-reflexive semantics à la Reichenbach (1947) (or Perry 1997) respects (a) and (b) by interpretation strategies of the following kind:

- an utterance of $I$ refers to the producer of that utterance,

- an utterance of here refers to the place of that utterance,

- an utterance of now refers to the time of that utterance.

According to occurrence-interpretation à la von Stechow (1979), on the other hand, occurrences of expressions in sentences are assigned context-independent meanings, i.e., functions from contexts to contents. But then these meanings, too, are defined by reference to utterances:

- an occurrence of $I$ in a sentence uttered in a context $c$ refers to the producer of the utterance of that occurrence in $c$,

- an occurrence of here in a sentence uttered in a context $c$ refers to the place of the utterance of that occurrence in $c$,

- an occurrence of now in a sentence uttered in a context $c$ refers to the time of the utterance of that occurrence in $c$.

3 Ede found (4) in an announcement for a class taught by Albert Visser at the Dutch Research School in Logic (http://turing.wins.uva.nl/ jve/ozsl/events.html), and it fits Hegel's observation: "The Here is e.g., the tree. I turn about and this truth has disappeared and has changed round into its opposite: the Here, is not a tree, but a house" Hegel (1967:152f.). We are indebted to Pirmin Stekeler-Weithofer for helping us to find this quotation. (5) is already cited in Kratzer (1978), in the very same connection. The translation is from Yuill (1982:12-14); we are very much indebted to the British Fontane expert Derek Glass for providing us with this source. Examples with changes of first-person pronouns are obviously rather rare, but Regine Eckardt reminds me they are not uncommon in (German) TV series, like Derrik or Der Kommissar. (6) is based on Bill Gates's reported average loss on the day mentioned; it may be comforting to learn that the stocks worth after the fall was still in the $\$ 50$ billion area. (7) is from von Stechow (1979:308). 
It is their reference to utterances that occurrence-interpretation and token-reflexive semantics have in common. The difference lies in reflexivity. In token-reflexive semantics, denotations or contents are assigned to utterances by reference to the utterances themselves; in occurrence-interpretation they are assigned to occurrences of expressions (in sentences) relative to contexts - so that the reference to utterances does not create any reflexivity.

The above rules of interpretation are mainly illustrative. Neither of the frameworks depends on their details. In particular, Angelika Kratzer (1978) has formulated more sophisticated token-reflexive interpretations of $I$ and now, which I take the liberty to generalize to the local deictic here:

- an utterance of $I$ refers to whoever counts as the producer of that utterance,

- an utterance of here refers to whatever place counts as the place of that utterance,

- an utterance of now refers to whatever time counts as the time of that utterance.

Kratzer motivates her interpretations by a number of examples involving inscriptions. If, e.g., someone carries a sign on her back saying $I a m d u m b$, we would naturally say that the sign expresses that the person that carries it is dumb. This is at odds with Reichenbach's interpretation inasmuch as the word $I$ is taken to refer to someone who does not utter anything herself. In order to deal with such cases, Reichenbach would thus either have to provide special interpretive strategies, or else even deny that they constitute utterances in the first place. On the other hand, Kratzer may identify the carrier of the sign as the person who counts as the producer of the inscription. ${ }^{4}$

4 Kratzer's distinctions shed an interesting light on two examples made famous by David Kaplan, whose logic of demonstratives makes arbitrary utterances of (i) come out true.

(i) I am here now.

The following counterexample is inspired by a similar scenario brought up by Hans Kamp in conversation. Professor Kamp is hard to meet in his office, i.e., per default one may assume he is not in. Consequently, his colleagues and students have given up knocking on his door to pick him up for lunch or coffee. However, being a social person, Kamp has lately started the habit of sticking a sign saying (i) to his office door whenever he happens to be around. One day when Kamp is away, someone tries to be funny by putting the sign on Kamp's door. One may argue that this silly behaviour results in a false utterance of (i), to wit an utterance about Professor Kamp. And Kratzer's semantics readily explains this: surely the person that counts as the utterer (Prof. Kamp) is not at the place that counts as the place of utterance (Kamp's office) at the time that counts as the time of utterance (while the sign is on the door).

The other sentence is:

(ii) 1 do not exist.

Kaplan claims that any utterance of (ii) is bound to be false. Hans Kamp (p.c.) counters, producing the case of a will to be announced at the testator's death, starting: You hear this now, while I no longer exist. Inasmuch as this is an utterance, it clearly expresses a true content. And this is not so because there has been a change (or death) of the utterer during the utterance, or because one need not exist in order to make an utterance, but rather because the person that counts as the utterer does not have to exist at the time that counts as the time of utterance. 
Kratzer's semantics is not only more sophisticated, it is also more general than tokenreflexivity à la Reichenbach. For the latter may be seen as a special case of the former, to wit as the result of adopting the following hypothesis as to who should count as the producer of an utterance - viz., the producer:

When it comes to interpreting an utterance $U$ :

- the producer of $U$ also counts as the producer of $U$,

- the place of $U$ also counts as the place of $U$,

- the time of $U$ also counts as the time of $U$.

Despite this generality, Kratzer's semantics is still in accordance with principle (b) above. For example, the interpretation of $I$ still depends on properties of the utterance, viz., who counts as its producer. However, there is a problem with (b). It is this: If the denotation of $I$ must be determined by reference to the properties of the utterance of $I$, it appears that any definition of the meaning of $I$ would have to involve the word $I$ itself. Arnim, e.g., takes the meaning of $I$ to be a partial function from contexts into functions that assign individuals to occurrences of $I$ (in sentences). (The functions are partial because they are only defined for contexts that contain utterances of $I$.) Now the problem is that the English word $I$ cannot be synonymous with its German cognate ich - if the meaning of the former relates to (utterances of) the word $I$, whereas that of the latter is defined in terms of (utterances of) the word $i c h$. But there can be no doubt that the two words are synonymous, that they have the same meaning. How else would it be possible to learn the meaning of ich by looking the word up in a bilingual dictionary?

This, then, is the problem I am concerned with in this paper. Before I address it, I will first go into the question of how meanings are systematically defined in occurrence-interpretation and compare the two approaches to Kaplan's logic of demonstratives.

\section{Context Dependence}

To be able to give our remarks some formal background, in this part I am going to present a simple formal language and show how to make meanings context-dependent in various ways. First I will define the language, give it an intensional semantics, and then I will introduce context-dependence, first in a Kaplanian, then in a occurrenceinterpretation way. The languages are intensional in the way of the lambda-categorial languages of Max Cresswell (1973), i.e., there is no separate type of truth-values. Instead sentences are assigned propositions. In contrast to Cresswell, I will use a 
functional syntax and the usual functional semantics. ${ }^{5}$ I will not discuss logic since in this paper I am concerned with semantics rather than logic. Specifically, nowhere will I define the important notions of a model, validity in a model, and logical validity for the languages considered.

\subsection{Syntax of $\mathfrak{Z}$}

\section{Definition}

(i) $p, e$, and $l$ are types.

(ii) If $\sigma$ and $\tau$ are types, so is $\langle\sigma, \tau\rangle$.

For every type $\sigma$, there is a set of constants $\operatorname{Con}_{\sigma}$ of that type. In particular, $I \in \operatorname{Con}_{e}$,

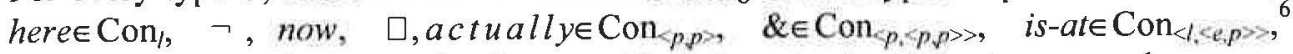
exists $\in \mathrm{Con}_{\langle e p\rangle}$, and utters-s.th. $\in \mathrm{Con}_{\langle e p\rangle}$. Then there is, for every type $\sigma$, a denumerably infinite set of variables $\operatorname{Var}_{\sigma}$ of type $\sigma$. Finally, for every type $\sigma$ there is a set Ex $x_{\sigma}$ of the expressions of type $\sigma$. The sets $\mathrm{Ex}_{\sigma}$ are defined to be the smallest sets satisfying the following conditions.

i. For every type $\sigma \in \mathrm{Con}_{\sigma}, \operatorname{Var}_{\sigma} \subseteq \mathrm{Ex}_{\sigma}$.

ii. If $\alpha \in \mathrm{Ex}_{<\sigma, \downarrow}$ and $\beta \in \mathrm{Ex}_{\sigma}$, then $\alpha \beta \in \mathrm{Ex}_{\tau}$;

iii. If $v \in \operatorname{Var}_{\sigma}$ and $\alpha \in \mathrm{Ex}_{\tau}$, then $\lambda v(\alpha) \in \mathrm{Ex}_{<\sigma, \downarrow}$;

iv. If $\alpha \in \mathrm{Ex}_{p}$ and $v \in \operatorname{Var}_{\sigma}$, then $\forall v \alpha \in \mathrm{Ex}_{p}$.

Finally, I will introduce the following abbreviations: Con $:=\mathrm{UCon}_{\sigma}, \mathrm{Var}:=\mathrm{UVar}_{\sigma}, \mathrm{Ex}$ $:=\mathrm{UEx}_{\sigma}$.

\subsection{Semantics without Context Dependence}

For every type $\sigma$, there is a set of denotations $D_{\sigma}$ of that type. $D_{p}:=\wp(W \times I)$, where $W$ is the set of worlds and I is the set of intervals. $\mathrm{D}_{e}$ is the set of possible individuals, and

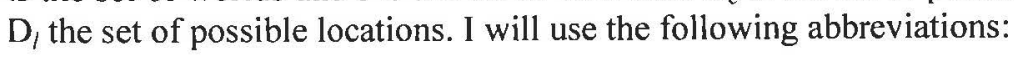

$\mathrm{D}_{<\sigma, \tau}:=\mathrm{D}_{\tau}^{\mathrm{D} \sigma} . \mathrm{D}:=\mathrm{UD}_{\sigma}$.

5 There is another important difference to Cresswell's approach. Cresswell collapses all domains in the domain of individuals and is therefore forced to use partial functions as elements of his domains in order to avoid paradox. We could easily implement these steps but have not, for reasons of simplicity.

6 as in I am now here. 
Now I will assign elements from these domains to all expressions. An assignment is a function $g$ from the set Var into the set $\mathrm{D}$, such that $\mathrm{g}(v) \in \mathrm{D}_{\sigma}$ if $v \in \operatorname{Var}_{\sigma}$. A partial valuation $\mathrm{V}$ is a partial function from the set Con into the set $\mathrm{D}$, such that the following holds:

- if $c \in \mathrm{Con}_{\sigma}$ and $\mathrm{V}(c)$ is defined, then $\mathrm{V}(c) \in \mathrm{D}_{\sigma}$,

- $\mathrm{V}(\neg)(\mathrm{p})=\mathrm{W} \times \mathrm{I} \backslash \mathrm{p}$,

- $\mathrm{V}(\&)(\mathrm{p})(\mathrm{q})=\mathrm{p} \cap \mathrm{q}$,

- $<w, t>\in V(\square)(p)$ iff for all $v \in W,<v, t>\in p$.

- With Kaplan I will assume that every individual exists at some time, in some world, so for no $\mathrm{a} \in \mathrm{D}_{e} \mathrm{~V}($ exists $)(\mathrm{a})=\emptyset$. Likewise, Kaplan assumes that if something is located, then it exists, and so will I: if $\langle\mathrm{w}, \mathrm{t}>\in \mathrm{V}($ is $-a t)(1)(\mathrm{a})$, then $<\mathrm{w}, \mathrm{t}>\in \mathrm{V}($ exists)(a).

- There is a distinguished individual $\mathbf{a}^{*}$, a distinguished location $\mathbf{I}^{*}$, a distinguished time $\mathbf{t}^{*}$, and a distinguished world $\mathbf{w} *$, s.t. $\mathrm{V}(I)=\mathbf{a}^{*}, \mathrm{~V}($ here $)=\mathbf{I}^{*}$, $<\mathrm{w}, \mathrm{t}>\in \mathrm{V}($ now $)(\mathrm{p})$ iff $<\mathrm{w}, \mathrm{t}^{*}>\in \mathrm{p}$, and $<\mathrm{w}, \mathrm{t}>\in \mathrm{V}($ actually $)(\mathrm{p})$ iff $<\mathrm{w}^{*}, \mathrm{t}>\in \mathrm{p}$.

Intuitively there is some utterance $u$, such that $a^{*}$ is the person that counts as the speaker of $u, l^{*}$ the place that counts as the place of $u, t^{*}$ the interval that counts as the time of $u$, and $w^{*}$ the world of $u$. But this explanation is only available for expressions which are actually uttered.

For the reasons given in the introduction, we cannot always assume that the person that counts as the speaker is, in the world of the utterance and at the time that counts as the time of the utterance, at the place that counts as the place of the utterance. Therefore I will not adopt Kaplan's assumption that $\left\langle\mathbf{w}^{*}, \mathbf{t}^{*}\right\rangle \in \mathrm{V}($ is-at $)\left(\mathbf{I}^{*}\right)\left(\mathbf{a}^{*}\right)$.

A valuation is a partial valuation $V$ as defined above such that $\operatorname{dom}(\mathrm{V})=\mathrm{Con}$. Given some arbitrary valuation $\mathrm{V}$, I will define for every $\alpha \in \mathrm{Ex}$ and assignment $\mathrm{g}$ the content of $\alpha$ wrt. $g$ and $\mathrm{V},[\alpha]^{\mathrm{V}, \mathrm{g}}$ for short. (If it is clear which $\mathrm{V} \mathrm{I}$ am talking about, $\mathrm{I}$ will write $[\alpha]^{\mathrm{g}}$ instead):

i. If $\alpha$ is a constant, then $[\alpha]^{\mathrm{g}}=\mathrm{V}(\alpha)$. If $\alpha$ is a variable, then $[\alpha]^{\mathrm{g}}=\mathrm{g}(\alpha)$.

ii. $[\alpha \beta]^{\mathrm{g}}=[\alpha]^{\mathrm{g}}\left([\beta]^{\mathrm{g}}\right)$,

iii. If $v \in \operatorname{Var}_{\sigma}$ and $\alpha \in \operatorname{Ex}_{\tau}$, then $[\lambda \nu(\alpha)]^{\mathrm{g}}=$ that function $\mathrm{f}$ in $\mathrm{D}_{<\sigma, \tau}$, such that for any $\mathrm{a} \in \mathrm{D}_{\sigma} \mathrm{f}(\mathrm{a})=[\alpha]^{\mathrm{g}[\mathrm{a} / v]}$,

iv. If $v \in \operatorname{Var}_{\sigma}$, then $[\forall v \alpha]^{\mathrm{g}}=\mathrm{\cap}_{\mathrm{a} \in \mathrm{D \sigma}}[\alpha]^{\mathrm{g}[\mathrm{a} / v]}$.

Since the domain $\mathrm{D}_{e}$ comprises all possible individuals, quantification in $\mathscr{L}$ is possibilist quantification. The usual world-bound quantifiers can be obtained by restricting quantification to individuals existing in a world via the predicate exists; see, e.g., Hughes \& Cresswell (1996:303f.) for details. 


\subsection{Kaplanian Context Dependence}

Kaplan's idea of context dependence is simply that the distinguished items $\mathbf{a}^{*}, \mathbf{I}^{*}, \mathbf{t}^{*}$, and $\mathbf{w}^{*}$ are not fixed once and for all, but vary with the context, such that every context determines a valuation. So let $\mathrm{C}$, the set of contexts, be a nonempty set. For every $\mathrm{c} \in \mathrm{C}$, $\mathrm{V}_{\mathrm{c}}$ will be a valuation as defined above. $[\alpha]^{\mathrm{V}, \mathrm{g}}$ is defined as above; I will also write $[\alpha]^{\mathrm{c}, \mathrm{g}}$ instead. $[\alpha]^{\mathrm{c}, \mathrm{g}}$ is the content of $\alpha$ in context c. For Kaplan, meaning does not equal content. Rather, meaning is a function from context to content; more precisely, for every expression $\alpha$ of type $\sigma$ the character of $\alpha$ wrt. an assignment $\mathrm{g}$ is that function $\mathrm{f}$ from $\mathrm{C}$ into $\mathrm{D}_{\sigma}$, such that for any $\mathrm{c} \in \mathrm{C}, \mathrm{f}(\mathrm{c})=[\alpha]^{\mathrm{c}, \mathrm{g}}$; and it is the character of $\alpha$ which is to be considered as the meaning of $\alpha$.

Kaplan's semantics is largely motivated by his quest for a logic of demonstratives and indexicals, and as I have said, we won't go into these matters here. Taken as a semantics for our indexicals, it has at least one important drawback. As I have already noted in the introduction, Kaplan's proposal does not admit of assigning different contents to different occurrences of the same indexical within the same sentence. But above we have seen that different occurrences should at least sometimes be treated differently.

Fortunately, there are different formal models of context dependence which do not suffer from these problems. One is token-reflexive semantics; the other one is Arnim's theory of occurrence-interpretation, to which we turn now.

\subsection{Occurrence-Interpretation}

Formally, occurrence-interpretation proceeds exactly as Kaplanian semantics does, the only difference being that it is now occurrences instead of expressions which are assigned context-dependent meanings.

But what is an occurrence? I will not go into the question of how occurrences ought to be analysed on an ontological level. For a straightforward answer to this question, see Arnim's paper. There may also be alternative answers. Maybe we don't know yet what occurrences really are. But we all know what occurrences are, i.e., how they occur in expressions and this may be all we need in order to be able to interpret them. Therefore, let me collect some useful facts about how they occur.

Occurrences are occurrences of expressions in expressions, so I will treat "occurrence" basically as a three-place predicate. Predications take the form "o is an occurrence of $\beta$ in $\alpha$ ". For reasons of simplicity I will assume that every expression occurs in itself, and only once, so, i.e.,

Fact 1: If $\alpha$ is an expression, then there is exactly one occurrence of $\alpha$ in $\alpha$.

Sometimes I will omit one (or two) of the final two places of the predicate. This should be taken as indicating existential quantification over the places I have omitted. For example, " 0 is an occurrence of $\beta$ " abbreviates "there is an $\alpha$, such that $\mathbf{o}$ is an occur- 
rence of $\beta$ in $\alpha$ ", "o is an occurrence in $\alpha$ " abbreviates "there is a $\beta$, such that $\mathbf{o}$ is an occurrence of $\beta$ in $\alpha$ " and "o is an occurrence" abbreviates "there are $\alpha$ and $\beta$, such that $o$ is an occurrence of $\beta$ in $\alpha$ ".

Occurrences uniquely determine the expressions they are occurrences of:

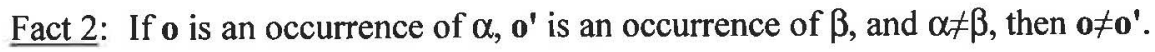

Another important fact about occurrences is that they may be structured. They may be constituents (or proper sub-occurrences) of one another. So let $\mathrm{O}$ be the set of occurrences and $<$ an ordering among members of $O$. Intuitively " $0<0$ " " stands for " 0 is a constituent of $a^{\prime \prime \prime}$.

Fact 3: $<$ is a binary relation on $\mathrm{O}$ which is transitive (if $\mathbf{0}^{\circ}<\mathbf{0}^{\prime}$ and $\mathbf{0}^{\prime}<\mathbf{0}^{\prime \prime}$, then $\mathbf{0}^{\prime \prime}<$ ) and asymmetric (if $\mathbf{0}^{\prime} \mathbf{0}^{\prime}$, then not $\mathbf{0}^{\prime}<\mathbf{0}$ ).

The relation of being in is inherited from constituent expressions to the occurrences they constitute, i.e.,

Fact 4: If $\mathrm{o}$ is an occurrence of $\beta$ in $\alpha$ and $\mathbf{o}^{\prime}<\mathbf{0}$ is an occurrence of $\gamma$ in $\beta$, then $\boldsymbol{o}^{\prime}$ is an occurrence of $\gamma$ in $\alpha$.

There is an important special case of the $<$ relation, namely the notion of immediate constituency, to which I turn now.

\section{Fact 5:}

(a) If $\mathrm{o}$ is an occurrence of $\alpha \beta$, then there is exactly one occurrence $\mathbf{o}^{\prime}$ of $\alpha$ and exactly one occurrence $0^{\prime \prime}$ of $\beta$ such that $\mathbf{o}^{\prime}$ and $\mathbf{0}^{\prime \prime}$ are immediate constituents of o.

(b) If $\mathrm{o}$ is an occurrence of $\lambda v \alpha$, then there is exactly one occurrence $o^{\prime}$ of $\alpha$, such that $\mathbf{o}^{\prime}$ is an immediate constituent of $\mathbf{o}$.

(c) If $\mathrm{o}$ is an occurrence of $\forall v \alpha$, then there is exactly one occurrence $o^{\prime}$ of $\alpha$, such that $\mathbf{o}^{\prime}$ is an immediate constituent of $\mathbf{o}$.

Fact 6: If $\mathbf{o}^{\prime}$ is an immediate constituent of $\mathbf{0}$, then $\mathbf{o}^{\prime}<\mathbf{0}$.

If there is a unique immediate constituent of $o$ which is an occurrence of $\alpha$, then I will denote it by $0^{\alpha}$.

Now I will assign elements from our domains to all occurrences. Let OCon be the set of occurrences of constants. A partial valuation $V$ is now a partial function from the set OCon into the set $\mathrm{D}$, such that the following holds:

- If $\mathrm{o}$ is an occurrence of an $\alpha \in \mathrm{Con}_{\sigma}$ and $\mathrm{V}(\mathbf{0})$ is defined, then $\mathrm{V}(\mathbf{0}) \in \mathrm{D}_{\sigma}$. 
- If $o$ is an occurrence of $\neg$, then $V(o)(p)=W \times I \backslash p$.

- If $o$ is an occurrence of \&, then $V(o)(p)(q)=p \cap q$.

- If 0 is an occurrence of $\square$, then $\langle w, t>\in V(o)(p)$ iff for all $v \in W,<v, t>\in p$.

- If $\mathrm{o}$ is an occurrence of exists, then for no $\mathrm{a} \in \mathrm{D}_{e} \mathrm{~V}(\mathbf{0})(\mathrm{a})=\emptyset$ and

- If $\mathbf{o}$ is an occurrence of is-at, $\mathbf{o}^{\prime}$ is an occurrence of exists, and $<\mathrm{w}, \mathrm{t}>\in \mathrm{V}(\mathbf{0})(\mathrm{l})(\mathrm{a})$, then $\langle\mathrm{w}, \mathrm{t}\rangle \in \mathrm{V}\left(\mathbf{o}^{\prime}\right)(\mathrm{a})$.

Finally, let $\mathbf{a}, \mathbf{l}$, and $\mathbf{t}$ be partial functions from the set of occurrences, such that $\mathbf{a}_{\mathbf{0}}$ is an individual (if defined), $\mathbf{I}_{\mathbf{0}}$ a location (if defined), and $\mathbf{t}_{\mathbf{0}}$ a time (if defined). Furthermore, there is a distinguished world $\mathbf{w}^{*}$. Intuitively, if there is some utterance $u$ of $\mathbf{0}$, then $\mathbf{a}_{\mathbf{0}}$ may be understood as the person that counts as the speaker of $u, I_{0}$ as the place that counts as the place of $u, t_{0}$ the interval that counts as the time of $u$ and $\mathbf{w}^{*}$ the world of $u$ (and the whole utterance of the expression o occurs in). But again, this explanation is only available if $\mathbf{o}$ is really uttered. Even then, $\mathbf{o}$ may have no such unique individual, time, or location, e.g., if what counts as the time of the utterance changes during the utterance. Therefore I have required that the functions be partial. I will, nevertheless, assume that the functions are always defined for occurrences of lexical items, i.e., constants.

Now I am finally able to state my conditions for the interpretation of our four indexicals.

- If $\mathbf{0}$ is an occurrence of $I, \mathrm{~V}(\mathbf{0})=\mathbf{a}_{\mathbf{0}}$.

- If $\mathbf{o}$ is an occurrence of here, $\mathrm{V}(\mathbf{0})=\mathbf{I}_{\mathbf{0}}$.

- If $\mathbf{o}$ is an occurrence of now, then $<w, t>\in V(\mathbf{o})(\mathrm{p})$ iff $<w, \mathbf{t}_{\mathbf{0}}>\in \mathrm{p}$.

- If $\boldsymbol{o}$ is an occurrence of actually, then $<\mathrm{w}, \mathrm{t}>\in \mathrm{V}(\mathbf{o})(\mathrm{p})$ iff $<\mathbf{w}^{*}, \mathrm{t}>\in \mathrm{p}$.

$\mathrm{V}$ is a valuation, iff it is a partial valuation which is a total function.

I will refrain from stating the straightforward classical semantics based on these (partial) valuations. Let us instead proceed directly to context dependence. Again, the general idea is simply that the distinguished functions $\mathbf{a}, \mathbf{I}, \mathbf{t}$, and the distinguished world $w^{*}$ are not fixed once and for all, but vary with the context such that every context determines a valuation. I will refer to the distinguished items for context $\mathrm{c}$ by a superscript c, e.g., as $\mathbf{a}^{\mathbf{c}}$. $\mathrm{C}$ is still the set of contexts. For every $c \in C, V_{c}$ will be a par- 
tial valuation as defined above. Let assignments be defined as usual. Now I am able to define $|\mathbf{o}|^{\mathrm{c}, \mathrm{g}}$, the content of occurrence $\mathrm{o}$ in context $\mathrm{c}^{7}$

i. If $\mathbf{o}$ is an occurrence of a constant, then $|\mathbf{o}|^{\mathrm{c}, \mathrm{g}}=\mathrm{V}_{\mathrm{c}}(\mathbf{0})$, if $\mathrm{V}_{\mathrm{c}}(\mathbf{0})$ is defined. Else $|\mathbf{o}|^{\mathrm{c}, \mathrm{g}}$ is undefined.

If $\mathbf{o}$ is an occurrence of a variable $v$, then $|\mathbf{o}|^{\mathrm{c}, \mathrm{g}}=\mathrm{g}(v)$.

ii. If $\mathbf{o}$ is an occurrence of $\alpha \beta$, then $|\mathbf{o}|^{\mathrm{c}, \mathrm{g}}$ is defined iff $\left|\mathbf{0}^{\alpha}\right|^{\mathrm{c}, \mathrm{g}}$ and $\mid \mathbf{0}^{\beta_{1}, \mathrm{~g}, \mathrm{~g}}$ are.

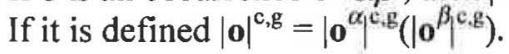

iii. If $v \in \operatorname{Var}_{\sigma}$ and $\alpha \in \mathrm{Ex}_{\tau}$, and $\mathbf{o}$ is an occurrence of $\lambda \nu \alpha$, then $|\mathbf{0}|^{\mathrm{c}, \mathrm{g}}$ is defined iff $\left|\mathbf{o}^{\alpha}\right|^{\mathrm{c}, \mathrm{g}}$ is. If it is defined, then $|\mathbf{o}|^{\mathrm{c}, \mathrm{g}}=$ that function $\mathrm{f}$ in $\mathrm{D}_{<\sigma, \tau\rangle}$, such that for any $a \in D_{\sigma} f(a)=\left|0^{\alpha}\right|^{c, g[a / v]}$.

iv. If $v \in \operatorname{Var}_{\sigma}$ and $\alpha \in \mathrm{Ex}_{p}$, and $\mathbf{o}$ is an occurrence of $\forall v \alpha$, then $|\mathbf{o}|^{\mathrm{c}, \mathrm{g}}$ is defined iff $\mid \mathbf{o}^{\alpha^{\mathrm{c}, \mathrm{g}}}$ is. If it is defined, then $|\mathbf{0}|^{\mathrm{c}, \mathrm{g}}=\bigcap_{\mathrm{a} \in \mathrm{Do}} \mid \mathbf{0}^{\alpha_{1} \mathrm{~g}[\mathrm{a} / \mathrm{y}]}$.

We may now go on and define, analogously to the above Kaplanian definition of "character of an expression", the character of an occurrence. This character may be called the meaning of the occurrence. But it is the meanings of expressions semantics is interested in. So what is the meaning of an expression in the present framework? If we learn the meaning of an expression we at least acquire the ability to understand arbitrary occurrences of that expression. Therefore I will define the meaning of $\alpha$ wrt. an assignment $g$ to be that function $\omega$ from those pairs of occurrences $\boldsymbol{0}$ of $\alpha$ and contexts $\mathrm{c}$, such that $|\mathbf{0}|^{\mathrm{c}, \mathrm{g}}$ is defined into contents of the appropriate type, such that if $\langle\mathbf{0}, \mathrm{c}\rangle$ is in the domain of $\omega$, then $\omega(\mathbf{o , c})$ is $|\mathbf{o}|^{\mathrm{c}, \mathrm{g}}$.

\section{The Less Certain Principle}

\subsection{The Problem}

Above I have provided for the possibility that $\mathrm{V}_{\mathrm{c}}$ may be partial, that it may not define values for every occurrence $\mathbf{0}$. I have done so for a very good reason. Let us say " 0 is

1 Cf. von Stechow (1979:331f.). The main difference lies in the fact that Arnim's valuations are relativized to an expression $\alpha$. This is meant to be an expression the occurrence to be evaluated occurs in (if it does not occur in $\alpha$, the valuation will be undefined). The extra relativization leads to the puzzling possibility that what is intuitively the same occurrence may receive different interpretations relative to different occurrences it is a part of (regarded as expressions it occurs in). A further difference is that where we define, solely for the purposes of exposition, the simpler notion of "content relative to a context", Arnim gives a recursive definition of context-dependent meanings, with a resulting different technical treatment of undefinedness. 
uttered in context c" if and only if there is an expression $\alpha$ such that $\mathbf{0}$ occurs in $\alpha$ and $\alpha$ is uttered in c. Now the only cases where there is a non-arbitrary way to define $V_{c}(\mathbf{o})$ are those where $\mathbf{o}$ is uttered in context $\mathbf{c}$. Then, and only then, can we uniquely identify an utterance $u$ which may be taken to be the utterance of $\mathbf{o}$ in the context. And this allows us (in most cases) ${ }^{8}$ to determine the values of $\mathbf{a}_{\mathbf{0}}, \mathbf{l}_{\mathbf{0}}$, and $\mathbf{t}_{\mathbf{0}}$ in that context, with the help of our general recipe on p.10.

On the other hand it is totally unclear how to determine $V_{c}(0)$ in contexts where something different from $\mathbf{o}$ is uttered (say, some item of another language) or, even worse, nothing is uttered at all. At least this holds for all conceptions of context I am aware of. Contexts may be identified with n-tuples of contextual parameters, with centered worlds or stages of possible individuals, or with utterances themselves. For all these conceptions it is possible to define the notion "o is uttered in context c"; but given the straightforward definitions for each case, it is still incomprehensible how to identify $\mathbf{a}_{0}, \mathbf{I}_{0}$, and $\mathbf{t}_{\mathbf{0}}$ for contexts in which $\mathbf{o}$ is not uttered. (Like Arnim I will not settle the issue of what contexts really are, and I will take the notion "o is uttered in c" as a primitive.)

So let us take $V_{c}$ to be partial, defined only for those $\mathbf{o}$ which are uttered in $\mathrm{c}$. This will lead to the following fact about meanings:

(PM) The meaning of $\alpha$ is only defined for pairs of occurrences $\mathbf{o}$ and contexts c, such that $\mathbf{0}$ is uttered in $\mathrm{c}$.

We may now define an utterance of an expression $\alpha$ to be a pair of an occurrence $\mathbf{o}$ of $\alpha$ and a context $\mathrm{c}$, such that $\mathrm{o}$ is uttered in c. (So far $\mathrm{l}$ have only dealt with utterances in a less technical sense. In the following I will mostly deal with the technical concept defined just now. I hope no confusion arises; the two concepts are closely related and may be put to equivalent use.) Then we can restate (PM) in the following form:

(PM) The meaning of $\alpha$ is only defined for utterances of $\alpha$.

Something quite like (PM) is adopted in Arnim's paper, too. On p. 330 he defines the notion " $\sigma$-meaning" (possible meaning of type $\sigma$ ). $\sigma$-meanings are functions from contexts, construed as world/time/place triples $\langle\mathrm{w}, \mathrm{t}, \mathrm{p}\rangle$, into contents. He notes that $\sigma$ meanings are partial functions and continues:

This is so, because if a particular $\sigma$-meaning $\omega$ is the meaning of some expression $\alpha$ then $\omega$ is defined for at most those indices $<w, t, p>$ such that $\alpha$ is uttered in $w$ at $t$ and $p$.

(PM) is a very natural principle, given the utterance-dependence of reference. If the determination of content is all there is to meaning, and if the content of a word at a

8 Even if $\mathbf{o}$ is uttered in context $\mathrm{c}$, there may be cases where $\mathbf{a}_{\mathbf{0}}, \mathbf{I}_{\mathbf{0}}$, and $\mathbf{t}_{\mathbf{0}}$ are undefined, e.g., if the speaker changes during $\mathbf{0}$; however, I have assumed that the speaker never changes during the utterance of a lexical item, so these cases can safely be ignored for the purpose of the definition of $\mathrm{V}_{\mathrm{c}}$. 
particular occasion is dependent on the properties of the utterance of the word at that occasion, then how could the meaning be applicable to occasions where the word is not uttered? - But now there is a problem.

The problem is that, according to (PM), no two different expressions could ever have the same meanings. This is so because no two different expressions have identical sets of utterances (this follows from Fact 2 above), therefore the domains of their meanings will differ.

That no two expressions could have the same meaning is a somewhat appalling consequence. Ede Zimmermann, who has been willing to bear it, has called it the "less certain principle (LCP)". ${ }^{9}$ But this seems to be a mild epithet. We simply know that some expressions are synonymous, for example, French je and English $I$, or French eau and English water, or J'ai faim and I am hungry. And we also know

(SYN) Synonymy is sameness of meaning.

So according to intuition and (SYN) there are cases of different expressions which have the same meaning. On the other hand our semantics implies that there are none. How should we react?

- Not by defying the intuitions. They are deep-rooted. Furthermore, they have explanatory value.

Firstly, that $I$ and $j e$ are synonymous may be taken to explain why they are intertranslatable. ${ }^{10}$ (On the other hand, if synonymy and intertranslatability are equivalent (or even only equivalent ceteris paribus) this seems to be a fact that is itself in need of explanation. Also note that sometimes interpreters don't give synonyms, e.g., if they put what they translate in indirect speech.) But secondly the existence of cases of synonymy (or near synonymy) explains why it is that we can sometimes learn the meaning of a word from a bilingual dictionary. Most of the time lexicographers don't define literal meanings. Maybe they don't even intend to give synonyms. But if you take a certain entry in your dictionary to tell you that $j e$ and $I$ mean the same, at least what you think this tells you is something true. If you rely on that information you have learned how the content of any arbitrary utterance of $j e$ (except in a quotation) is determined. So we should take the intuitions seriously. But how?

- Not by trying to define a better notion of synonymy. Any definition other than that synonymy is sameness of meaning just misses the point.

- Maybe by invoking the notion of extrapolation. Let me explain.

9 Zimmermann (1997:147). Versions of the LCP have also been defended by Nelson Goodman $(1949,1953)$ and Catford (1965).

10 Or so it is said - e.g., by Putnam (1988:29): "But meaning, we should recall, if it is anything, is what we try to preserve in translation." 


\section{.2 Extrapolating MEANINGs}

Aaybe we could say $I$ and $i c h$ are identical in meaning, but in another sense of "meanng", a sense that is not in conflict with, but derivable from occurrence-interpretation. lou may object that speakers are not aware that there are different senses at issue. But $\mathrm{n}$ the study of meaning it ought to be a familiar phenomenon that there is no single recise theoretical notion that matches all the pre-theoretical intuitions. And often, this s so without the layman's awareness that there are different senses of "meaning" inrolved. Sometimes "meaning" is best explicated as truth conditions, sometimes as cogitive significance, sometimes as character, sometimes as propositional concept. ${ }^{11}$ The heoretician has analysed the layman's use of "meaning" into several different notions, ind he has been compelled to do so because there is nothing that answers all the laynan's intuitions, taken together. So there seems to be nothing wrong if we add just inother notion which yields the intuitively correct predictions about synonymy. Let his notion be called MEANING. But, since we think occurrence-interpretation is esientially correct, these MEANINGs ought to be dependent on meanings.

The LCP is a result of the fact that meanings of different expressions have different fomains. The domain of the meaning of $I$ is the set of utterances of $I$, the domain of the neaning of $i c h$ is the set of utterances of $i c h$. A straightforward way to get rid of this roblem would be to extend these domains. Why not take the union of the two sets as he common domain for the two MEANINGs? Only then do $I$ and $i c h$ have even the shance to be synonymous. Still this would only help for $I$ and $i c h$, but not for je, so we should join all relevant domains. In effect, in order to avoid any acting ad hoc, we projose to take the same domain for every MEANING, namely the set of all utterances of arbitrary possible expressions.

But now the problem arises of how the values of the respective MEANINGs for the extra elements in their domains are defined. There is a straightforward answer to this question, namely "by extrapolation". Simply extend the old functions to the new elements. Aren't they basically the same? In the case of $I$ the function is basically: take the utterer. In the case of $i c h$, again, the function is basically: take the utterer. Of course, the two functions are only basically the same, since they have different domains. But if we abstract from this, so the story of the extrapolationist goes, no difference remains. And extrapolation to arbitrary utterances is abstraction from this difference.

Unfortunately the notion of "extrapolation" is particularly unpopular. Both Goodman's "new riddle of induction" (Goodman 1955: chapter 3) and "Kripke's Wittgenstein" (Kripke 1982) are based on a deep scepticism about it. It seems as if we can't specify rules by just pointing to a few samples and then add "go on in the same way." But that is just what I have been proposing! Now others have defended extrapolation. For example, David Lewis proposes to rescue extrapolation by appealing to naturality. He points to the fact that only some extensions of a given series may be called natural, and some are more natural than others. Therefore it is at least not completely undeter-

"Cf. the variety of notions of content discussed in Perry (1997:599-609). 
mined how a series might be extended, see, e.g., Lewis $(1983,1992)$. (Lewis claims that we need some notion of metaphysical naturalness here. Now what is metaphysically natural may not be accessible to the individual. But since we want to explain our faculty to extend a function from utterances of $I$ to utterances of $j e$ we need standards of naturalness that are within our control. I conclude that one needs a notion of psychological naturalness here.) One also needs naturalness in order to explain how it is that children can grasp the meaning of $I$ in English from a few samples. Meanings are acquired by extrapolation, Goodman's and Kripke's scepticism notwithstanding.

But if this is true, why say that first meanings are extrapolated and then, only afterwards, MEANINGs are extrapolated rather than that both are extrapolated in one fell swoop? We shouldn't have MEANING besides meaning. Let us have it instead. Note also that your possessing meanings (and MEANINGs alike) should not be regarded as you having the functions stored as infinite lists somewhere in your head. It should rather be regarded as you having certain semantic faculties. For example, possessing the meaning of $I$ consists in part in the faculty to understand utterances of $I$. Possessing the MEANING of $I$ consists in the former faculty and also in the faculty to learn the meaning of $j e$ from a bilingual dictionary. Since we have no clue that the two faculties are acquired at different stages, and since the mechanism of acquiring them is the same, there is no reason to separate them.

Summing up, resorting to extrapolation is not entirely misguided: we need extrapolation to explain language learning, or so I think. But it seems much more sensible to assume that our meanings have already been extrapolated than to extrapolate them for my purpose of explaining how it is that we can learn the meaning of $j e$ from a dictionary. So finally I have reached the conclusion that my notion of meaning was too restricted after all.

\subsection{Kaplanian MEANINGs}

Kaplanian semantics fares better in this respect. This is so because Kaplan does not restrict his characters to utterances. The Kaplanian meaning of $I$ that we sketched above, e.g., is totally expression independent. We can give German ich and French je exactly the same meanings, for instance. This is so, because here we are not required, for the purpose of evaluation of an arbitrary expression, to stick to those contexts where the expression is uttered.

One can define the latter notion within Kaplan's framework. Let's say an expression $\alpha$ is uttered in context $\mathrm{c}$ iff in $\mathrm{c}_{\mathrm{w}}, \mathrm{c}_{\mathrm{a}}$ counts as the speaker of $\alpha$ at time $\mathrm{t}$ and place $\mathrm{p}$. Kaplan uses the term "utterance" for context/expression-pairs in which the expression is uttered (quite in agreement with our terminological decision above); but arbitrary context/ $\alpha$-pairs he calls occurrences of $\alpha$ in a context. (This decision may be a bit confusing in the context of the present paper.) Let us call those Kaplanian occurrences where nothing is uttered in the context at all or where the expression uttered is not the expression uttered in the context "impossible utterances". These have been branded as useless in Zimmermann (1997:145): "I cannot imagine why any theory would want to 
make any (in principle untestable) predictions about what a sentence expresses in a (possible) situation in which it is not uttered." I don't think this critique is justified. First, we have already seen a decent motivation for impossible utterances: they are what enables Kaplan to have synonymy. The introduction of impossible utterances can simply be seen as a means of getting rid of the reference to the particular expression in the meaning of that expression. But what about the problem that predictions about impossible utterances are in principle untestable? What is meant here is presumably not an empirical test, but rather the kind of test we perform when summoning our intuitions about what an expression would express in twin earth. However, Zimmermann is right in saying that these intuitions (the "tests") never concern impossible utterances. Now, does this mean all choices of contents for impossible utterances are equal? Such that

"for utterances of $I$ take the utterer;

take the addressee for any other occurrence in which something is uttered;

take Manfred for all other occurrences"

would be as good a rule for $I$ as the above "take whoever counts as the speaker in the context"? Then, for any two expressions there would be (a) pairs of meanings which make them synonymous and (b) pairs of meanings which make them non-synonymous and both the (a) and the (b) assignments of meaning would be as equally correct.

But this is not so, since synonymy itself is a fact of the matter. That $I$ and je are synonymous is a fact of the matter since this explains, among other things, how we can learn the meanings of French words from a dictionary. Therefore the above crazy rule for $I$ is incorrect, because it predicts that any Kaplanian rule for $j e$ that is in accordance with what we know of the content of utterances of je disagrees with the above rule on those utterances.

So Kaplan was on the right track. His meanings may be termed "already extrapolated". On the other hand his meanings are empirically incorrect, because they admit of no occurrence-dependence. The remaining question is how to find a semantics that has the virtues of the Kaplanian semantics without its vices.

\section{Simple Expressions}

Now there seems to be a trivial solution to the problem at hand. Simply proceed as Kaplan did! Let us make our valuations total rather than partial and let the content of every occurrence be defined for all contexts. Then, our meanings could indeed be identical for $I$ and $j e$, because the domains no longer disagree. Unfortunately, it can't be all that simple. Such a solution would require our contexts to possess magical linguistic powers. How could a context be able to determine for any occurrence that does not occur in the context who counts as the utterer of that occurrence? The situation is different from the Kaplanian case, because at least on some conceptions of context, the distinguished items (agent, location, time, and world) can be directly extracted from the 
context without reference to expressions or occurrences. (Of course Kaplan has to pay for this advantage in terms of applicability. It is not entirely clear in his framework how to determine for a given utterance what the context of that utterance is.)

I will now show how to remove the expression-dependence from occurrence-interpretation. In this section I will concentrate on simple expressions. For example, we want $I$ and $j e$ to come out synonymous, therefore the relevant meanings should share their domain and agree on the shared domain. As indicated above, I will construct a domain as big as possible by letting the meaning of $I$ and $j e$ be defined for any utterance (in the technical sense) which is equipped with someone that counts as its speaker. Still, I am aiming at a generalization of our definition of meaning in the foregoing section.

I can no longer define MEANINGs in terms of a prior definition of contents though, because now the content of an utterance $<\mathbf{0}$, c $>$ will depend on the MEANING considered, e.g., $<\mathbf{0}, \mathbf{c}>$ has a different content if evaluated wrt. the MEANING of $I$ or if evaluated wrt. the MEANING of here.

Now what are the MEANINGs of $I$, here, now, and actually? As I have said, for some utterances what counts as the speaker, time, and place may not be defined. So I have to assume that the MEANINGs of $I$, now and here are truly partial. But for every utterance where they are defined, they will be defined by the familiar functions into contents. In particular,

- If $\mathbf{a}_{\mathbf{0}}^{\mathbf{c}}$ is defined, $\llbracket I \rrbracket(\mathbf{o}, \mathbf{c})=\mathbf{a}_{\mathbf{0}}^{\mathbf{c}}, \llbracket I \rrbracket(\mathbf{o}, \mathbf{c})$ is undefined else.

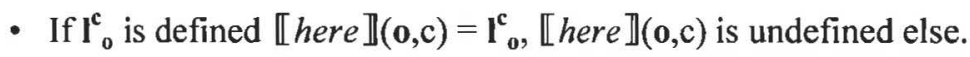

- If $\mathbf{t}_{\mathbf{}_{0}}$ is defined $<w, t>\in \llbracket n o w \rrbracket(\mathbf{o}, \mathbf{c})(\mathrm{p})$ iff $<w, \mathbf{t}_{\mathbf{0}}^{\mathbf{c}}>\in \mathrm{p}$, [now $\rrbracket(\mathbf{o}, \mathrm{c})$ is undefined else.

- $<w, \mathrm{t}>\in \llbracket$ actually $\rrbracket(\mathbf{o}, \mathrm{c})(\mathrm{p})$ iff $<\mathbf{w}^{*^{\mathrm{c}}, \mathrm{t}}>\in \mathrm{p}$.

\section{Complex Expressions}

Let me now turn to the question of how the MEANINGs of complex expressions are determined. We will again want to extend the domain of the MEANING of $\alpha$ beyond utterances of $\alpha$. This is so because

(8) I am now finished

and

(9) Ich bin jetzt fertig

should come out synonymous but wouldn't if the two MEANINGs had different domains - viz., the utterances of (8) and (9), respectively. 
But now we face an immediate problem. It is the problem of defining relevant suboccurrences. Let me explain. Let me first say how we evaluate utterances of (8). Let $\underline{I}$ be the unique occurrence of $I$ in (8). Now

$<\mathrm{w}, \mathrm{t}>\in \mathbb{\complement}(8) \rrbracket(\mathbf{0}, \mathrm{c})$ iff at $\mathrm{w}$ and $\mathrm{t}, \llbracket I \rrbracket(\underline{I}, \mathrm{c})=\mathbf{a}_{l}^{\mathrm{c}}$ is finished.

But if we extend the domain of $\llbracket(8) \rrbracket$, the question arises of how to treat an utterance $<\mathbf{0}, \mathrm{c}\rangle$ that is in the domain of $\llbracket(8) \rrbracket$ without being an utterance of (8). We need to know where to apply the MEANING of $I$. What replaces reference to $\underline{I}$ here? So the problem is how to define, for any occurrence $0^{\prime}$ in (8), the sub-occurrence of 0 which is relevant for the evaluation of $\mathbf{o}^{\prime}$.

Given our two example sentences there is a very simple solution that suggests itself. Presented with an utterance of (9) one could take the relevant sub-context for the evaluation of the content of now to be the utterance of the item that has the same structural position in the sentence, namely jetzt. Following this line of reasoning, one would have to restrict synonymy to cases of intensional isomorphism. But this is far too restrictive. For example, it should at least in principle be possible to express the same meaning with a different number of words. Indeed, it is even tempting to say that the French sentence

(10) Fini!

is synonymous to (8) and (9) although it lacks structure. (Although later on I will find a reason to say that (10) is not synonymous to either (8) or (9), I will still use this example for purposes of illustration. It should be easy to substitute other examples of sentences which are synonymous, but yet not identical in structure.)

You might try to find other solutions to the problem. I doubt that there are any. Anyway, I think that already the search is misguided. So far my extension of domains has been motivated by the observation that one can learn languages from a bilingual dictionary. If we are told that $I$ and $j e$ are synonymous, we learn how to evaluate any arbitrary utterance $<\mathbf{0 , c}\rangle$ (given we know who counts as the producer of $\mathbf{o}$ in $\mathbf{c}$ ). But if we are told that (8) and (9) are synonymous, things are different. Suppose you don't know German and are told that (8) and (9) are synonymous. Are you now able to determine the content of any arbitrary utterance $<\mathbf{0}, \mathrm{c}>$ of (9)?

I don't think so. Even if you know who counts as the speaker of $\mathrm{o}$ in $\mathrm{c}$ and the times that count, in c, as the times of all sub-occurrences of $\mathbf{o}$, you still can't say what proposition has precisely been expressed unless you are told that now and jetzt are synonymous and hence, that the relevant sub-occurrence for now is o's sub-occurrence of jetzt.

To sum up, the problem of defining the relevant sub-occurrences has no solution and ought to have no solution. But then we're stuck with our search after a notion of MEANING which allows different sentences to have the same MEANING, at least if we want these MEANINGs to be defined in a compositional way. Should we give in?

In the next section I will propose a way out. 


\section{MEANINGs and Synonymy}

This section comes in three parts. In the first subsection I will informally present the main ingredients of the recursive definition of MEANINGs which will then be given in the second subsection. That system will still suffer from the LCP, though. Only in the last subsection will I indicate how to take the MEANINGs defined in the second and obtain a notion of synonymy which does not suffer from the LCP.

\subsection{Preliminaries}

The upshot of the last section was that there is no principled way to define relevant sub-occurrences. Instead I want to propose that relevant sub-occurrences are stipulated, and that contents are assigned to utterances only relative to stipulations. Formally, we will treat stipulations as functions that map occurrences onto occurrences, e.g., the suboccurrences of (8) onto the sub-occurrences of (9).

Now there are usually different possible stipulations for the same pair of sentences. For example, they might differ as to what is the relevant sub-occurrence for the evaluation of now in (9). Of course in this case there is only one correct choice, but you might not know which one. If you are told that (8) and (9) are synonymous and you only know English and no German, you might not know to which occurrence in (9) to apply the meaning of now.

In effect, I am proposing that there is an additional component to linguistic knowledge which has largely gone unnoticed so far. While people are aware that in order to know a language you need to know its syntax and its meanings, they seldom pay attention to the fact that if they want to apply a meaning to an utterance they also need to know to which component utterances to apply which meanings. The reason that this is usually overlooked is that the answer is trivial in the case of one's own language. You only need this kind of information if you want to determine the content of an utterance of a foreign language, and the only thing you know about that utterance is that it is an utterance of a sentence which is synonymous to some sentence of your own language.

By saying this is an additional component of linguistic knowledge, I also want to apologize for not treating it here in any formal detail. I will only define meaning proper, and therefore, I will not say what it means to know to which component utterances to apply which meanings. Consequently, my MEANINGs will almost never allow the determination of a unique content for any utterance. Even if we are evaluating an utterance of the sentence itself, it will be possible to choose different stipulations.

Nevertheless, we should impose at least one constraint on the range of possible stipulations. It is that the relative order of indexicals in the expression to be evaluated should be respected by the stipulation. For example, if we want to evaluate 
(11) Now is before now

vis á vis an utterance $<\mathbf{0 , c}>$ of

(12) Jetzt ist vor jetzt

'Now is before now'

we shouldn't be able to stipulate that the relevant sub-occurrence of $\mathbf{o}$ for the evaluation of the first occurrence of now is the second occurrence of jetzt and vice versa. If we would, we could hardly distinguish (12) and

(13) Jetzt ist nach jetzt

'Now is after now'

neither could we account for the odd flavour of (12). ${ }^{12} 1$ will therefore assume that, for every occurrence $\mathbf{0}$, its sub-occurrences of constants are linearly ordered by $\boldsymbol{c}^{13}$

As usual, " $0 \subseteq 0$ " " abbreviates " $0 \subseteq 0$ " or $0=0$ "”.

\subsection{MEANINGs}

Let me now introduce the formal system that embodies these ideas. The reader should be warned that the definitions have now reached a complexity that may make them not easy to read. For example, my MEANINGs will take four arguments before they yield a content. So the definitions are somewhat overcrowded with subscripts and arguments.

This does not hold for partial valuations. These are defined as in 2.2. I will repeat the definitions for convenience. A partial valuation $\mathrm{V}$ is a partial function from the set Con into the set $\mathrm{D}$, such that the following holds:

- if $c \in \mathrm{Con}_{\sigma}$ and $\mathrm{V}(c)$ is defined, then $\mathrm{V}(c) \in \mathrm{D}_{\sigma}$,

- $\mathrm{V}(\neg)(\mathrm{p})=\mathrm{W} \times \mathrm{I} \backslash \mathrm{p}$,

- $V(\&)(p)(q)=p \cap q$,

- $\langle\mathrm{W}, \mathrm{t}>\in \mathrm{V}(\square)(\mathrm{p})$ iff for all $\mathrm{v} \in \mathrm{W},\langle\mathrm{v}, \mathrm{t}>\in \mathrm{p}$.

- For no $\mathrm{a} \in \mathrm{D}_{e} \mathrm{~V}($ exists $)(\mathrm{a})=\varnothing$ and if $\langle\mathrm{w}, \mathrm{t}>\in \mathrm{V}($ is-at)(1)(a), then $\langle\mathrm{w}, \mathrm{t}>\in \mathrm{V}($ exists $)(\mathrm{a})$.

- There is a distinguished individual $\mathbf{a}^{*}$, a distinguished location $\mathrm{I}^{*}$, a distinguished time $\mathbf{t}^{*}$, and a distinguished world $\mathbf{w}^{*}$, s.t. $\mathrm{V}(I)=\mathbf{a}^{*}, \mathrm{~V}($ here $)=\mathbf{I}^{*}$, $<\mathrm{w}, \mathrm{t}>\in \mathrm{V}($ now $)(\mathrm{p})$ iff $<\mathrm{w}, \mathrm{t}^{*}>\in \mathrm{p}$, and $<\mathrm{w}, \mathrm{t}>\in \mathrm{V}($ actually $)(\mathrm{p})$ iff $<\mathbf{w}^{*}, \mathrm{t}>\in \mathrm{p}$.

12 I owe these examples to Ede Zimmermann (p.c.), as well as the whole point presented in the paragraph.

13 Of course this relation should be formally defined, but I will skip the details of a rather obvious, but tedious definition, here. 
Our present idea of context dependence is now simply that the distinguished items $\mathbf{a}^{*}$, $I^{*}, t^{*}$, and $\mathbf{w}^{*}$ are not fixed once and for all, but vary with the utterance, such that every utterance $<\boldsymbol{0}, c\rangle$ determines a valuation $V_{<0, c} .1$ will, as before, refer to the distinguished items $\mathbf{a}^{*}, \mathbf{l}^{*}, \mathbf{t}^{*}$, and $\mathbf{w}^{*}$ of an utterance $<\mathbf{0 , c}>$ as $\mathbf{a}^{\mathbf{c}}{ }_{0}, \mathbf{I}^{\mathbf{c}}, \mathbf{t}^{\mathbf{c}}$, and $\mathbf{w}^{*} \mathbf{c}$, respectively.

Now let us define our stipulations.

\section{Definition:}

For any expression $\alpha$ let $\alpha_{0}$ be the unique occurrence of $\alpha$ in $\alpha$.

Let $\alpha$ be an expression and $\mathrm{o}$ be any occurrence.

$\mathrm{f}$ is an $\alpha / \boldsymbol{o}$-map iff

$f$ is a function from the set of sub-occurrences of $\alpha_{0}$ into the set of sub-occurrences of $\mathbf{0}$,

such that if $\mathbf{o}^{\prime}$ and $\mathbf{o}^{\prime \prime}$ are occurrences of indexical constants ${ }^{14}$ in $\alpha$, then $0^{\prime} \subseteq o^{\prime \prime}$ iff $\mathrm{f}^{\prime}\left(\mathrm{o}^{\prime}\right) \subseteq \mathrm{f}\left(\mathrm{o}^{\prime \prime}\right)$.

$\mathrm{f}$ is a stipulation if it is an $\alpha / \mathbf{0}$-map for some expression $\alpha$ and occurrence $\mathbf{o}$.

Let us say expression $\alpha$ occurs in $\beta$ iff there is some occurrence of $\alpha$ in $\beta$. In the following I will try to evaluate an expression $\alpha$ wrt. to $\beta / 0$-maps for some expression $\beta$ such that $\alpha$ occurs in $\beta$, the reason being that both the utterance evaluated and the stipulation made should stay constant during the evaluation of a complex expression, so stipulations should stay applicable even if we turn to subexpressions of the expression we have begun with. I will say that $f$ is admissible for $\alpha$ and o iff $f$ is an $\beta / 0$-map for some expression $\beta$, such that $\alpha$ occurs in $\beta$. Obviously, if $\mathrm{f}$ is admissible for $\alpha$ and 0 , then it is admissible for $\gamma$ and $\mathbf{o}$, where $\gamma$ is any expression that occurs in $\alpha$.

Following our former use $\alpha_{0}{ }^{\beta}$ will be the unique immediate constituent of $\alpha_{0}$ which is an occurrence of $\beta$, i.e., the topmost occurrence of $\beta$ in $\alpha$.

Now we can define, for arbitrary expressions $\alpha$, stipulations $\mathrm{f}$, assignments $\mathrm{g}$, and utterances $\langle\mathbf{0}, \mathrm{c}\rangle$, such that $\mathrm{f}$ is admissible for $\alpha$ and $\mathbf{o}: \llbracket\left[\alpha \rrbracket^{\mathrm{f}, \mathrm{g}}(\mathbf{o}, \mathrm{c})\right.$, the content of $\alpha$ wrt. $\mathrm{f}, \mathrm{g}$, and $<\mathbf{0}, \mathrm{c}>$.

i. $\quad$ Let $\mathbf{o}^{\prime}=\mathrm{f}\left(\alpha_{\mathbf{0}}\right)$. If $\alpha$ is a constant, then $\llbracket \alpha \rrbracket^{\mathrm{f}, \mathrm{g}}(\mathbf{o}, \mathrm{c})=\mathrm{V}_{<\mathbf{0}^{\prime}, \mathrm{c}}(\alpha)$,

if $\mathrm{V}_{<0,0}(\alpha)$ is defined.

Else $\llbracket \alpha \rrbracket^{f, g}(o, c)$ is undefined.

If $\alpha$ is a variable $v$, then $\llbracket \alpha \rrbracket^{\mathrm{f}, \mathrm{g}}(\mathbf{0}, \mathrm{c})=\mathrm{g}(v)$.

ii. If $\alpha=\beta \gamma$, then $\llbracket \alpha \rrbracket^{\mathrm{f}, \mathrm{g}}(\mathbf{o}, \mathrm{c})$ is defined iff $\llbracket \beta \rrbracket^{\mathrm{f}, \mathrm{g}}\left(\mathrm{f}\left(\alpha_{0}{ }^{\beta}\right), \mathrm{c}\right)$ and $\llbracket \gamma \rrbracket^{\mathrm{f}, \mathrm{g}}\left(\mathrm{f}\left(\alpha_{0}{ }^{\gamma}\right), \mathrm{c}\right)$ are. If it is defined $\llbracket \alpha \rrbracket^{\mathrm{f} g}(\mathbf{o}, \mathrm{c})=\llbracket \beta \rrbracket^{\mathrm{f} g}\left(\mathrm{f}\left(\alpha_{0}{ }^{\beta}\right), \mathrm{c}\right)\left(\llbracket \gamma \rrbracket^{\mathrm{f}, \mathrm{g}}\left(\mathrm{f}\left(\alpha_{0}{ }^{\gamma}\right), \mathrm{c}\right)\right)$.

14 A constant $\alpha$ is indexical iff $\mathrm{V}_{\langle\mathbf{0}, \mathrm{c}\rangle}(\alpha) \neq \mathrm{V}_{\left\langle\mathbf{0}^{\prime}, c^{c^{\prime}}\right\rangle}(\alpha)$ for some $\mathbf{0}, \mathbf{0}^{\prime}, \mathrm{c}, \mathrm{c}^{\prime}$. 
iii. If $v \in \mathrm{Var}_{\sigma_{-}}$and $\beta \in \mathrm{Ex}_{\tau}$, and $\alpha=\lambda v \beta$, then $\llbracket \alpha \rrbracket^{\mathrm{f}, \mathrm{g}}(\mathbf{o}, \mathrm{c})$ is defined iff $\left[\beta \rrbracket^{\mathrm{f}, \mathrm{g}}\left(\mathrm{f}\left(\alpha_{0}{ }^{\beta}\right), \mathrm{c}\right)\right.$ is. If it is defined, then $\llbracket \alpha \rrbracket^{f \cdot g}(o, c)=$ that function $h$ in $D_{<\sigma, \triangleright \triangleright}$, such that for any $\mathrm{a} \in \mathrm{D}_{\mathrm{o}} \mathrm{h}(\mathrm{a})=\llbracket\left[\beta \rrbracket^{\mathrm{f}, \mathrm{g}[\mathrm{a} / \mathrm{w}]}\left(\mathrm{f}\left(\alpha_{\mathrm{o}}^{\beta}\right), \mathrm{c}\right)\right.$.

iv. If $v \in \mathrm{Var}$ and $\beta \in \mathrm{Ex}_{p}$, and $\alpha=\forall v \beta$, then $\llbracket \alpha \rrbracket^{\mathrm{f}, \mathrm{g}}(\mathbf{o}, \mathrm{c})$ is. defined iff $\llbracket \beta \rrbracket^{\mathrm{f}, \mathrm{g}}\left(\mathrm{f}\left(\alpha_{\mathrm{o}}{ }^{\beta}\right), \mathrm{c}\right)$ is. If it is defined, then $\llbracket \alpha \rrbracket^{\mathrm{f}, \mathrm{g}}(\mathbf{o}, \mathrm{c})=\mathrm{n}_{\mathrm{a} \in \mathrm{D \sigma}} \llbracket \beta \rrbracket^{\mathrm{f}, \mathrm{g}[\mathrm{a} / \mathrm{v}]}\left(\mathrm{f}\left(\alpha_{0}{ }^{\beta}\right), \mathrm{c}\right)$.

As noted before, the number of sub- and superscripts is quite demanding. In order to facilitate understanding, let me go through an example in some detail.

Let me consider again sentences (8) and (9).

(8) I am now finished.

(9) Ich bin jetzt fertig.

In accordance with our syntax I will look at slightly regimented versions, though.

(8') now finished I

(9') jetzt fertig ich

For ease of presentation I will use the following notation: $\underline{\alpha}$ denotes the unique occurrence of $\alpha$ in $\left(8^{\prime}\right)$ or $\left(9^{\prime}\right)$.

Now let us consider the following $\left(8^{\prime}\right) /\left(9^{\prime}\right)_{0}$-map f:

f: (8') now finished I

(9') ietzt fertig ich

It is easy to see that the map preserves the order of occurrences of indexicals. Being an $\left(8^{\prime}\right) /\left(9^{\prime}\right)_{0}$ - map, it is admissible for $\left(8^{\prime}\right)$ and $\left(9^{\prime}\right)_{0}$. Now consider a context $c$ in which $\left(9^{\prime}\right)$ has been uttered, such that $\left\langle\left(9^{\prime}\right)_{0}, c\right\rangle$ is an utterance. We want to evaluate $\left(8^{\prime}\right)$ wrt. f, an arbitrary assignment $\mathrm{g}$, and $\left\langle\left(9^{\prime}\right)_{0}, \mathrm{c}\right\rangle$. We can assume that the content of every constant in $\left(8^{\prime}\right)$ is defined in the relevant contexts, such that the same holds for every complex expression, including $\left(8^{\prime}\right)$ itself. Therefore,

$$
\begin{aligned}
& \llbracket\left(8^{\prime}\right) \rrbracket^{\mathrm{f}, \mathrm{g}}\left(\left(9^{\prime}\right)_{0}, \mathrm{c}\right)=\llbracket \text { now } \rrbracket^{\mathrm{f}, \mathrm{g}}(\mathrm{f}(\text { now }), \mathrm{c})\left(\llbracket \text { finished } I \rrbracket^{\mathrm{f}, \mathrm{g}}(\mathrm{f}(\text { finished } I), \mathrm{c})\right) \\
& =\llbracket \text { now } \rrbracket^{\mathrm{f}, \mathrm{g}}(\mathrm{f}(\text { now }), \mathrm{c})\left(\llbracket \text { finished } \rrbracket^{\mathrm{f}, \mathrm{g}}(\mathrm{f}(\text { finished }), \mathrm{c})\left(\llbracket I \rrbracket^{\mathrm{f}, \mathrm{g}}(\mathrm{f}(\underline{\underline{n}}, \mathrm{c}))\right)\right. \\
& =\mathrm{V}_{<\mathrm{f}(\text { now }), \mathrm{c}>}(\text { now })\left(\mathrm{V}_{<\mathrm{f}(\text { finished }), \mathrm{c}}>(\text { finished })\left(\mathrm{V}_{<\mathrm{f}(I), \mathrm{c}>}(I)\right)\right)
\end{aligned}
$$

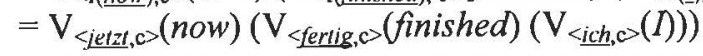


So, the meaning of finished is applied to the utterance of fertig in context $\mathrm{c}$, the meaning of now is applied to the utterance of jetzt, and the meaning of $I$ to the utterance of $i c h$.

Let us assume that for arbitrary $0: \mathrm{V}_{<0 . c}($ finished $)$ is that function $\omega$, such that for every individual a: $\omega(a)=\{\langle w, t>| a$ is finished in $w$ at $t\}$. Hence

$\mathrm{V}_{<f \text { ertig, } \mathrm{c}>}($ finished $)\left(\mathrm{V}_{<\underline{i c h, c}>\mathrm{c}}(I)\right)=\left\{<\mathrm{w}, \mathrm{t}>\mid \mathbf{a}_{\underline{\text { ich } h}}^{\mathbf{c}}\right.$ is finished in $\mathrm{w}$ at $\left.\mathrm{t}\right\}$.

Therefore,

$\llbracket\left(8^{\prime}\right) \rrbracket^{\mathrm{f}, \mathrm{g}}\left(\left(9^{\prime}\right)_{\mathbf{0}}, \mathrm{c}\right)=\mathrm{V}_{\text {jetzl, } \mathrm{c}}($ now $)\left(\left\{<\mathrm{w}, \mathrm{t}>\mid \mathbf{a}^{\mathrm{c}}{ }_{\text {ict }}\right.\right.$ is finished in $\mathrm{w}$ at $\left.\left.\mathrm{t}\right\}\right)$

$=\left\{\langle\mathrm{w}, \mathrm{t}\rangle \mid \mathbf{a}^{\mathrm{c}}{ }_{\text {ich }}\right.$ is finished in $\mathrm{w}$ at $\left.\mathrm{t}_{\text {tetzly }}^{\mathrm{e}}\right\}$

Let $\mathbf{t}_{\text {jeezy }}^{\mathbf{c}}$ be the November, 23rd, 2000, 17:10 and let $\mathbf{a}_{\underline{\text { ich }} \mathbf{c}}^{\mathbf{c}}$ be Manfred. Then,

$\llbracket\left(8^{\prime}\right) \rrbracket^{\mathrm{f}, \mathrm{g}}\left(\left(9^{\prime}\right)_{0}, \mathrm{c}\right)=$

$\{<w, t>\mid$ Manfred is finished in w at November, 23rd, 2000, 17:10\}.

I should finally say what the meaning of an expression is according to the present approach. But this can be read off directly from the above definition of content. Let $U$ be the set of utterances and $\mathrm{F}$ be the set of stipulations.

The MEANING of $\alpha$ wrt. $\mathrm{g}$ is that partial function $\omega$ from $\mathrm{F} \times \mathrm{U}$ into $\mathrm{D}$, such that

(i) $\quad \omega(\mathrm{f},<\mathbf{0}, \mathrm{c}>)$ is defined iff $\mathrm{f}$ is admissible for $\alpha$ and $\mathbf{0}$ and $\llbracket \alpha \rrbracket^{\mathrm{f}, \mathrm{g}}(\mathbf{o}, \mathrm{c})$ is defined,

(ii) if defined $\omega(\mathrm{f},<\mathbf{0}, \mathrm{c}>)=\llbracket \alpha \rrbracket^{\mathrm{f}, \mathrm{g}}(\mathbf{o}, \mathrm{c})$.

\subsection{Synonymy}

So what about the examples that have motivated our search for a generalization of occurrence-interpretation? What about the synonymy of $I$ and je, the synonymy of (8) and (9) and the synonymy of (10) and (11)? The examples all come out wrong! This is so because our meanings are as expression-dependent as ever, due to the expression dependence of the notion of an admissible stipulation. For example, the MEANING of (8) is only defined for pairs $\langle f,\langle\mathbf{0}, c\rangle\rangle$, such that $f$ is an (8)/0-map, while the MEANING of (9) is only defined for pairs $\langle\mathbf{f},\langle\mathbf{0}, \mathrm{c}\rangle\rangle$, such that $\mathrm{f}$ is an (9)/o-map, and it is these different domains that make the two functions differ. So different expressions always have non-identical MEANINGs and the LCP still rules.

But there is a way out: While synonymy is sameness of meaning, this does not mean that two synonymous meanings literally mean identical things. We could settle with less. Instead of demanding that (8) and (9) have identical meanings, we could say that they merely have the same meanings. 
So we could read "sameness" in (SYN) as "identity in a loose and popular sense". Is The OED interprets "same" as "identical" but acknowledges the existence of "modified senses" as "7. applied to an object as having the same attributes with another or with itself at another time". ${ }^{16}$

But I will still use the above definition of MEANING in order to define the required notion of sameness. Let me first define the auxiliary notion of weak MEANING.

The weak MEANING of $\alpha$ wrt. $\mathrm{g}$ is that partial function $\omega$ from $\mathrm{U}$ into Pow(D), such that $\omega(<0, \mathrm{c}>)=$

$\left\{\mathrm{x} \mid \exists \mathrm{f}\right.$ : $\mathrm{f}$ is admissible for $\alpha$ and $\mathbf{o}, \llbracket \alpha \rrbracket^{\mathrm{f} g}(\mathbf{o}, \mathrm{c})$ is defined and $\left.\mathrm{x}=\llbracket \alpha \rrbracket^{\mathrm{f} g}(\mathbf{o}, \mathrm{c})\right\}$

Finally, let us say two expressions are synonymous iff they share the same weak MEANING. It may again be helpful to consider two examples.

First, if we assume that for every utterance $\mathrm{u}, \mathrm{v}_{\mathrm{u}}(j e)$ is defined iff $\mathrm{V}_{\mathrm{u}}(I)$ is, and if defined $\mathrm{V}_{\mathrm{u}}(j e)=\mathrm{V}_{\mathrm{u}}(I)$, then

the weak MEANING of $j e$ is that partial function $\omega$ from $\mathrm{U}$ into $\mathrm{D}$, such that

$\omega(<0, \mathrm{c}>)$

$=\left\{\mathrm{x} \mid \exists \mathrm{f}: \mathrm{f}\right.$ is admissible for $j e$ and $\mathbf{o}, \llbracket j e \rrbracket^{\mathrm{f} \cdot \mathrm{g}}(\mathbf{o}, \mathrm{c})$ is defined and

$\left.\mathrm{x}=\llbracket j e \rrbracket^{\mathrm{f}, \mathrm{g}}(\mathbf{o}, \mathrm{c})\right\}$

$=\left\{\mathrm{x} \mid \exists \mathrm{f}: \mathrm{f}\right.$ is admissible for $j e$ and $\mathbf{0}, \mathrm{V}_{<\mathbf{0}, \mathrm{c}>}(j e)$ is defined and $\left.\mathrm{x}=\mathrm{V}_{<\mathbf{0}, \mathrm{c}>}(j e)\right\}$

$=\left\{\mathrm{x} \mid \mathrm{V}_{<0, \boldsymbol{c}\rangle}(I)\right.$ is defined and $\left.\mathrm{x}=\mathrm{V}_{<0, c>}(I)\right\}$.

But this is also the $\omega$ which is the weak MEANING of $I$. Therefore, $I$ and je come out synonymous.

Secondly, consider $\left(8^{\prime}\right)$ and $\left(9^{\prime}\right)$. Let us assume that for every utterance $u$ :

- $\quad \mathrm{V}_{\mathrm{u}}($ fertig $)=\mathrm{V}_{\mathrm{u}}($ finished $)$;

- $\mathrm{V}_{\mathrm{u}}($ jetzt $)$ is defined iff $\mathrm{V}_{\mathrm{u}}($ now $)$ is; if defined $\mathrm{V}_{\mathrm{u}}($ jetzt $)=\mathrm{V}_{\mathrm{u}}($ now $)$;

- $\quad \mathrm{V}_{\mathrm{u}}(i c h)$ is defined iff $\mathrm{V}_{\mathrm{u}}(I)$ is; if defined $\mathrm{V}_{\mathrm{u}}(i c h)=\mathrm{V}_{\mathrm{u}}(I)$.

15 I owe the phrase to Armstrong (1997), who has taken it from Bishop Butler (1736).

16 A remaining difficulty is that normally when speakers use a loose and popular sense of "same" they are aware that they do. And this is not so in the present case. Ask someone who knows that $I$ and $i c h$ have the same meaning. She will either say that this is so in the strictest sense, or, more likely, she will not even understand your question. But this is what is always the case when a pretheoretical concept is replaced by a family of precise concepts by science. 
We have seen above that (for arbitrary h, such that $h$ is admissible for $\alpha$ and $o$ and $\llbracket\left(8^{\prime}\right) \rrbracket^{\mathrm{h}, \mathrm{g}}(\mathbf{o}, \mathrm{c})$ is defined)

$\llbracket\left(8^{\prime}\right) \rrbracket^{\mathrm{h}, \mathrm{g}}(\mathbf{0 , c})=\mathrm{V}_{<\mathrm{h}(\text { now }), \mathrm{c}>}($ now $)\left(\mathrm{V}_{<\mathrm{h}(\text { finished }), \mathrm{c}>}(\right.$ finished $\left.)\left(\mathrm{V}_{<\mathrm{h}\left(I_{\mathrm{c}} \mathrm{c}>\right.}(I)\right)\right)$.

Likewise, (for arbitrary $\mathrm{h}$, such that $\mathrm{h}$ is admissible for $\alpha$ and $\mathbf{o}$ and $\llbracket\left(8^{\prime}\right) \rrbracket^{\mathrm{h}, \mathrm{g}}(\mathbf{o}, \mathrm{c})$ is defined)

$\llbracket\left(9^{\prime}\right) \rrbracket^{\mathrm{h}, \mathrm{g}}(\mathbf{0}, \mathrm{c})=\mathrm{V}_{<\mathrm{h}(j \mathrm{etz} f), \mathrm{c}>}(j e t z t)\left(\mathrm{V}_{<\mathrm{h}(\text { erenig }), \mathrm{c}>}(\right.$ fertig $)\left(\mathrm{V}_{<\mathrm{h}(i \mathrm{ich})_{\mathrm{L}}>}(\right.$ ich $\left.\left.)\right)\right)$.

Observe that $\mathrm{f}$, defined on p. 342 above is a 1-1 map from the sub-occurrences of $\left(8^{\prime}\right)$ onto the sub-occurrences of $\left(9^{\prime}\right)$. Given these presuppositions, we can easily show that the two weak MEANINGS agree. I will show this by showing that arbitrary values of these meanings agree.

Claim: For any arbitrary utterance $<\mathbf{0}, \mathrm{c}>$ :

$\left\{\mathrm{x} \mid \exists \mathrm{h}: \mathrm{h}\right.$ is admissible for $\alpha$ and $\mathrm{o}, \llbracket\left(8^{\prime}\right) \rrbracket^{\mathrm{h}, \mathrm{g}}(\mathrm{o}, \mathrm{c})$ is defined and $\mathrm{x}=$ $\left.\llbracket\left(8^{\prime}\right) \rrbracket^{\mathrm{h}, \mathrm{g}}(\mathbf{o}, \mathrm{c})\right\}=$

$\left\{\mathrm{x} \mid \exists \mathrm{h}: \mathrm{h}\right.$ is admissible for $\alpha$ and $\mathbf{o}, \llbracket\left(9^{\prime}\right) \rrbracket^{\mathrm{h}, \mathrm{g}}(\mathbf{o}, \mathrm{c})$ is defined and $\mathrm{x}=$ $\left.\llbracket\left(9^{\prime}\right) \rrbracket^{\mathrm{h}, \mathrm{g}}(\mathbf{o}, \mathrm{c})\right\}$.

Proof:

Let $\mathrm{x}$ be an element in the first set. I.e., there is an $h$ which is admissible for $\left(8^{\prime}\right)$ and $0, \llbracket\left(8^{\prime}\right) \rrbracket^{\mathrm{h}, 8}(0, c)$ is defined and $x=$

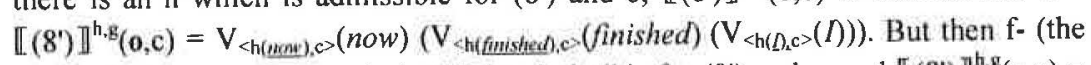
inverse function of $\mathrm{f})$ is such that hf-is admissible for $\left(9^{\prime}\right)$ and $\mathbf{o}$, and $\llbracket\left(8^{\prime}\right) \rrbracket^{\text {h.g }}(\mathbf{o}, \mathrm{c})=$ $\llbracket\left(9^{\prime}\right) \rrbracket^{\mathrm{hf}, \mathrm{g}}(\mathbf{o}, \mathrm{c})$. This is so, because

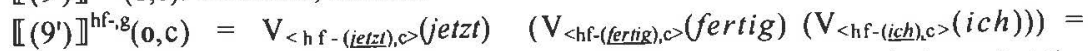

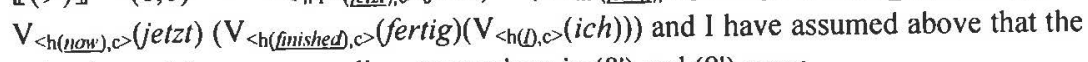
valuations of the corresponding expressions in $\left(8^{\prime}\right)$ and $\left(9^{\prime}\right)$ agree.

Therefore every element in the first set is an element in the second. But precisely the same argument can be applied to the other direction (with $f$ instead of $f-$ ), so the two sets are the same.

The second example may suggest that the definition of synonymy presupposes intensional isomorphism, but that is not so. Note that the machinery of stipulations is only relevant for the interpretation of indexical expressions, so even if two non-indexical expressions are as different in form as you can imagine, they can still be synonymous. Nor does that mean that indexical sentences have to be intensionally isomorphic in order to be synonymous. This can be shown by the following simple consideration. First it can be shown that if $A$ and $A^{\prime}$ are synonymous and also $B$ and $B^{\prime}$, then $A \& B$ is synonymous to $A^{\prime} \& B^{\prime}$. And if you conjoin a nonindexical sentence to an indexical one, you get an indexical sentence. Therefore, if $A$ and $A^{\prime}$ are synonymous and indexical 
and $B$ and $B^{\prime}$ are synonymous and nonindexical, then $A \& B$ is synonymous to $A^{\prime} \& B^{\prime}$. But $A \& B$ need not be intensionally isomorphic to $A^{\prime} \& B^{\prime}$ because, being non-indexical, $B$ need not be isomorphic to $\mathrm{B}^{\prime}$.

The precise conditions my definitions impose on the structure of synonyms are not easy to state, and I will not do so here. But I should mention a case where these conditions still appear to be too restrictive at first sight. This is the case of

(10) Fini!

(10) is not synonymous to (8) or (9) according to our approach, because for some utterances there are possible contents of $\left(8^{\prime}\right)$ that $(10)$ could not have. This contrasts with our first intuitive judgements about (10).

Look at the interpretation of $\left(8^{\prime}\right)$ and the following interpretation of Finil, which is as close as can be to the former.

$\llbracket\left(8^{\prime}\right) \rrbracket^{\mathrm{f} \cdot \mathrm{g}}(\mathbf{o}, \mathrm{c})=\left\{<\mathrm{w}, \mathrm{t}>\mid \mathbf{a}_{\mathrm{f}(l)}^{\mathrm{c}}\right.$ is finished in $\mathrm{w}$ at $\left.\mathbf{t}^{\mathrm{c}}{ }_{\mathrm{f}(\underline{n o w})}\right\}$

$\mathrm{V}<\mathbf{0}, \mathrm{c}>($ Fini! $)=\left\{<\mathrm{w}, \mathrm{t}>\mid \mathbf{a}_{\mathbf{0}}{ }^{\mathrm{c}}\right.$ is finished at $\left.\mathbf{t}^{\mathrm{c}}{ }_{0}\right\}$

Now consider a two-part utterance $<\mathbf{0}, \mathbf{c}\rangle$, such that who counts as the speaker changes during the utterance.

$$
\begin{gathered}
\mathbf{0} \\
0^{\prime} 0^{\prime \prime}
\end{gathered}
$$

$\mathbf{a}^{\mathbf{c}}$ : Tarzan Jane

$\mathbf{t}^{\mathbf{c}}: \quad 1 \quad 2$

Let $\mathrm{f}$ be any $\left(8^{\prime}\right) / 0$-map, such that $\mathrm{f}(\underline{\text { now }})=1$, and $\mathrm{f}(\underline{\underline{l}})=$ Jane. Then

$\llbracket\left(8^{\prime}\right) \rrbracket^{\mathrm{f}, \mathrm{g}}(\mathbf{o}, \mathrm{c})=\{<\mathrm{W}, \mathrm{t}>\mid$ Jane is finished in $\mathrm{w}$ at 1$\}$.

But it is not possible for $(10)$ to have such a content. If $h$ is any (10)/o-map, then

$\llbracket$ Fini! $\rrbracket^{f, g}(\mathbf{o}, \mathrm{c})=\left\{<\mathrm{w}, \mathrm{t}>\mid \mathbf{a}_{\mathrm{h}(\mathbf{0})}^{\mathbf{c}}\right.$ is finished in $\mathrm{w}$ at $\left.\mathbf{t}_{\mathrm{h}(\mathbf{0})}^{\mathbf{c}}\right\}$,

because of the above valuation and the semantics of constants. We can clearly see that $\mathbf{a}^{\mathbf{c}}$ and $\mathbf{t}^{\mathbf{c}}$ are bound to be applied to the same occurrence, so we could either get $\{<\mathrm{w}, \mathrm{t}>\mid$ Jane is finished in $\mathrm{w}$ at 2$\}$ or $\{<\mathrm{w}, \mathrm{t}>\mid$ Tarzan is finished in $\mathrm{w}$ at 1$\}$, but never

$\{<w, t>\mid$ Jane is finished in $w$ at 1$\}$. Because the weak MEANINGs differ for at least one argument, they are different, therefore $\left(8^{\prime}\right)$ and $(10)$ are nonsynonymous.

Now does this indicate that our notion of synonymy is still too restrictive? I don't think so. Rather, the example shows that there is a difference in meaning between ( $\left.8^{\prime}\right)$ and 
$\left(9^{\prime}\right)$ on the one hand and (10) on the other which has gone unnoticed so far. Suppose the multi-speaker utterance you are interpreting is really an utterance of $\left(9^{\prime}\right)$. Suppose you only know the meaning of (10) and are told that $\left(9^{\prime}\right)$ means the same as (10). Then something you can't anticipate is that there is the possibility of interpreting an utterance of $\left(9^{\prime}\right)$ in the way we did above. Whereas, on the other hand, if you only know the meaning of $\left(8^{\prime}\right)$ and are told that $\left(9^{\prime}\right)$ means the same, then you can anticipate the possibility that an utterance of $\left(8^{\prime}\right)$ might have this interpretation. Since our aim is to predict what speakers learn by learning about synonyms, this clearly indicates that there is a difference in meaning between $\left(8^{\prime}\right)$ and $(10)$.

On the other hand we should be able to explain why $\left(8^{\prime}\right)$ and (10) look synonymous. But we can. The reason is simple. Multi-speaker utterances are fairly far-fetched possibilities and in making synonymy claims we normally don't consider possibilities that remote.

\section{Conclusion}

Occurrence-interpretation can be generalized so that the resultant notion of meaning gives a better approximation of our linguistic competence. In particular, the generalized notion can be taken to predict how come we can learn languages by being told which expressions mean the same.

Fini! ${ }^{17}$

\section{References}

Armstrong, David (1997). A World of States of Affairs. Cambridge: Cambridge University Press.

Butler, Joseph (1736). The Analogy of Religion, Natural and Revealed, to the Constitution and Course of Nature. London: J. M. Dent.

Catford, John C. (1965). A Linguistic Theory of Translation. London: Oxford University Press.

Cresswell, Maxwell J. (1973). Logics and Languages. London: Methuen.

Goodman, Nelson (1949). On Likeness of Meaning. Analysis 10. 1-7.

Goodman, Nelson (1953). On Some Differences about Meaning. Analysis 13. 90-96.

17 Wishful thinking: the real work may not even have begun. Nowhere have I addressed the problems that arise if one tries to apply the account to real natural languages. And specifically I presently do not have much to say about how occurrence-interpretation relates to LF-interpretation. 
Goodman, Nelson (1955). Fact, Fiction, and Forecast. Cambridge, MA: Harvard University Press.

Hegel, Georg Wilhelm Friederich (1967). The Phenomenology of Mind. Translated by J. B. Baillie. New York: Harper \& Row.

Hughes, George E. \& Maxwell J. Cresswell (1996). A New Introduction to Modal Logic. London/New York: Routledge.

Kaplan, David (1989). Demonstratives: An Essay on the Semantics, Logic, Metaphysics and Epistemology of Demonstratives and Other Indexicals. In: Joseph Almog, John Perry \& Howard Wettstein (eds.) Themes from Kaplan. New York: Oxford University Press. 481-563.

Kratzer, Angelika (1978). Semantik der Rede. Kontexttheorie - Modalwörter-Konditionalsätze. Königstein/Ts.: Skriptor.

Kripke, Saul (1982). Wittgenstein on Rules and Private Language. Oxford: Blackwell.

Lewis, David (1983). New Work for a Theory of Universals. The Australasian Journal of Philosophy 61. 343-377.

Lewis, David (1992). Meaning without Use: Reply to Hawthorne. The Australasian Journal of Philosophy 70. 106-211.

Montague, Richard (1970). Universal Grammar. Theoria 36. 373-398.

Perry, John (1997). Indexicals and Demonstratives. In: Bob Hale \& Crispin Wright (eds.) A Companion to the Philosophy of Language. Oxford: Blackwell. 586-612.

Putnam, Hilary (1988). Representation and Reality. Cambridge, MA: MIT Press.

Reichenbach, Hans (1947). Elements of Symbolic Logic. London: Collier-MacMillan.

Stechow, Arnim von (1979). Occurrence-Interpretation and Context-Theory. In: Daniele Gambarara, Franco Lo Piparo \& Giulianella Ruggiero (eds.) Linguaggi e formalizzazioni. Rome: Bulzoni. 307-347.

Yuill, William E. (1982). Seeing Ourselves As Others See Us: A German Novelist in Victorian Scotland. Schools Scottish Studies Review 1. 12-22.

Zimmermann, Thomas E. (1997). The Addressing Puzzle. In: Wolfgang Künne, Albert Newen, Martin Anduschus (eds.) Direct Reference, Indexicality, and Propositional Attitudes. Stanford: CSLI. 133-153.

Zucchi, Alessandro (1993). The Language of Propositions and Events. Dordrecht: Kluwer. 